\title{
Atmospheric monitoring at the Norwegian Antarctic station Troll: measurement programme and first results
}

\author{
Georg Hansen, ${ }^{1}$ Katrine Aspmo, ${ }^{2}$ Torunn Berg, ${ }^{3}$ Kåre Edvardsen, ${ }^{1}$ Mmarkus Fiebig, ${ }^{2}$ Roland Kallenborn, ${ }^{2}$ \\ Terje Krognes, ${ }^{2}$ Chris Lunder, ${ }^{2}$ Kersten Stebel, ${ }^{2}$ Norbert Schmidbauer, ${ }^{2}$ Sverre Solberg ${ }^{2}$ \& Karl Espen Yttri ${ }^{2}$ \\ 1 Norwegian Institute for Air Research, Polar Environmental Centre, NO-9296 Tromsø, Norway \\ 2 Norwegian Institute for Air Research, P.O. Box 100, NO-2027 Kjeller, Norway \\ 3 Department of Chemistry, Norwegian University of Science and Technology, NO-7491 Trondheim, Norway
}

\author{
Keywords \\ Antarctica; atmosphere; pollution.

\section{Correspondence} \\ Georg Hansen, Norwegian Institute for Air \\ Research, Polar Environmental Centre, \\ NO-9296 Tromsø, Norway. E-mail: \\ ghh@nilu.no
}

doi:10.1111/j.1751-8369.2009.00134.x

\begin{abstract}
The Troll Atmospheric Station in Antarctica $\left(72^{\circ} 01^{\prime} \mathrm{S}, 2^{\circ} 32^{\prime} \mathrm{E}, 1309 \mathrm{~m}\right.$ a.s.l.) was established and put into operation in early 2007. The main foci of the measurement programme are pollution and aerosols in the transition zone between the coastal zone and the inland ice plateau, complementing existing observation programmes along the Antarctic coast and on the Antarctic Plateau. After one year of operation, the monitoring programme is fully operative, and a comprehensive set of data is being analysed. As far as comparable data are available, there is satisfactory agreement between previous and new data. Both aerosol data and measurements of pollution indicate the episodic influence of coastal air masses throughout the year. Background values of medium long-lived pollutants such as $\mathrm{CO}, \mathrm{O}_{3}$ and $\mathrm{Hg}$ are up to $50 \%$ lower than at corresponding Arctic sites (depending on the season), but are still significant. Total ozone and UV doses manifest the recurring Antarctic stratospheric ozone hole, which was moderately severe, but very persistent in 2007. Specific episodes of elevated aerosol concentration and mercury activation are currently under detailed investigation, and will be published separately.
\end{abstract}

In 2005, the Norwegian Antarctic station Troll was upgraded from a summer station to a year-round station with its own airfield. The facility is located in Dronning Maud Land at $72^{\circ} 01^{\prime} \mathrm{S}, 2^{\circ} 32^{\prime} \mathrm{E}$, at an elevation of $1275 \mathrm{~m}$ a.s.l., and approximately $220 \mathrm{~km}$ from the Antarctic coast. The main station building is on a nunatak, i.e., on rock ground, whereas the airfield is located on the blue ice, about $7 \mathrm{~km}$ north of the station. Troll Station is one of the few stations located on the slope of the Antarctic ice sheet (and the only one that is operated year-round). These stations are exposed to varying influence from the Antarctic plateau and the Southern Ocean, whereas the environment at other long-term activity stations is either coastal or high-elevation continental in nature.

One of the major goals of the Troll Station is to establish a comprehensive and continuous monitoring programme of important atmospheric parameters in this transition and mixing zone between subpolar oceanic and central polar ice sheet air masses. Of particular interest are the following issues:
- extent of polar spring surface ozone/elementary mercury depletion events;

- characterization of optical, and in-situ, physical and chemical properties of aerosols, with a focus on longrange transport events;

- levels and temporal variability (seasonal, year-to-year) of inorganic and organic pollution (persistent organic pollutants [POPs], non-methane hydrocarbons [NMHCs], hydroflourocarbons [HFCs], perfluorocarbons [PFCs], carbon monoxide [CO], ozone);

- levels of ultraviolet irradiation, with a focus on ozone hole conditions, and its influence on ozone and mercury chemistry;

- establishing an archive of large whole-air samples taken twice a year at the expected minimum and maximum of the annual cycle.

The strong focus on pollution issues was chosen to complement the existent atmospheric monitoring and research programmes at other stations in the region, such as the German Neumayer station, the South African 


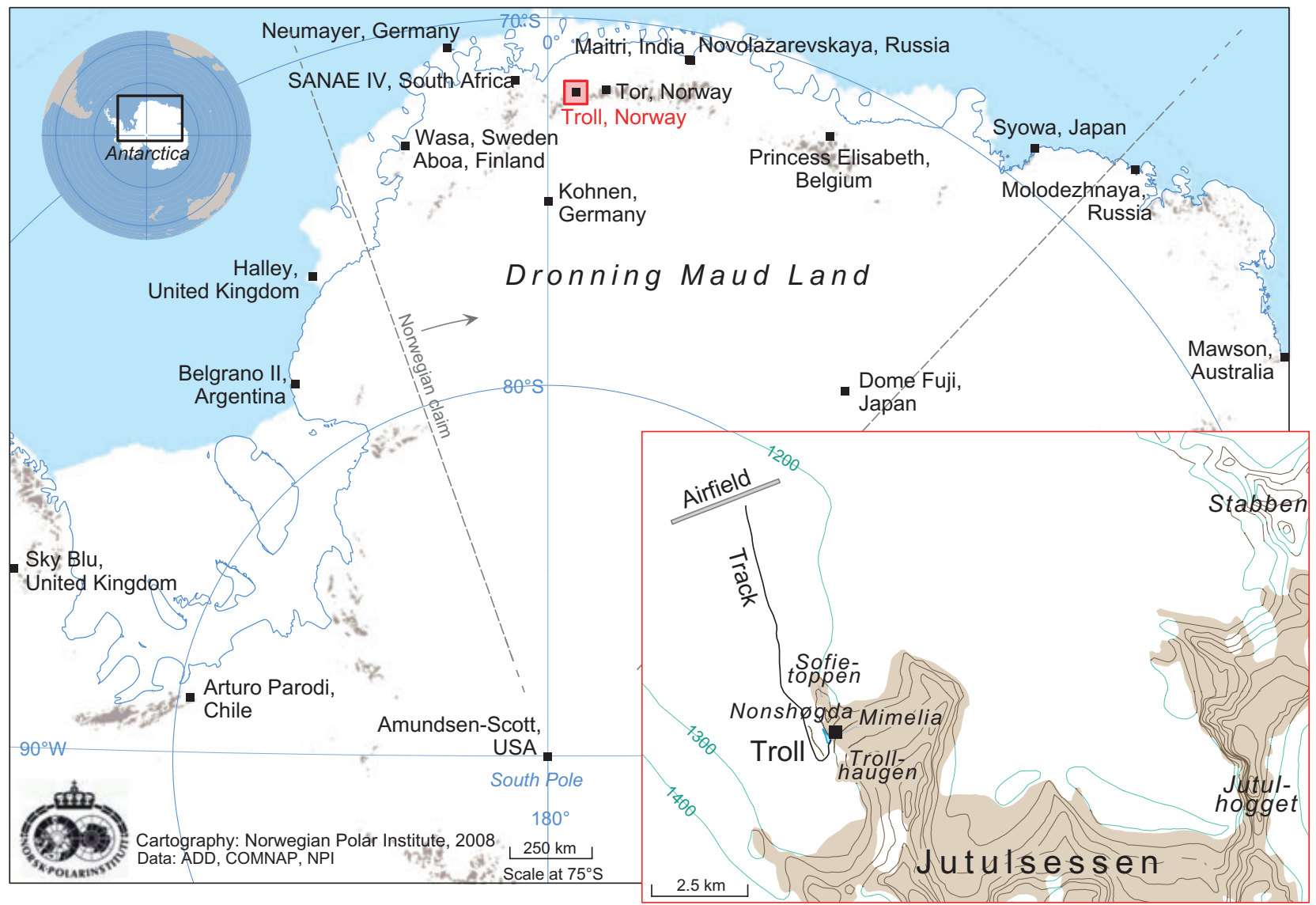

Fig. 1 The location of Troll Station in Antarctica. The Troll Atmospheric Station is about $2000 \mathrm{~m}$ east of the main building, toward Trollhaugen. The distance between the main station and the airfield is approximately $7 \mathrm{~km}$. (Map courtesy of the Norwegian Polar Institute.)

station SANAE IV, the British Halley Research Station and the Japanese Syowa Station.

In this paper we give an overview of the measurement programme, the instruments used and the operational experience after an almost complete annual cycle of measurements. Publications on more focused scientific results are in preparation.

\section{Technical infrastructure}

The expected extremely low background levels of pollution in this region required a site for the atmospheric station that is not exposed to local pollution from the station main building or motorized activity at all. This excluded the option to place the instruments at the Troll Station main building. Co-locating the atmospheric station with the Troll satellite receiver station at $1415 \mathrm{~m}$ a.s.l., on top of the nearby hill ridge, Sofietoppen, which is about $600 \mathrm{~m} \mathrm{NNW}$ of the main station, was also considered. However, the remote site would have seriously inhibited daily accessibility during winter, which was regarded as necessary, at least during the initial operation phase. Therefore, it was decided to establish a stand-alone platform consisting of two containers approximately $200 \mathrm{~m}$ from the main station building, upwind of the predominant wind direction (northeasterly), and at an elevation of $34 \mathrm{~m}$ above the main station. If data collected during the first year implied too frequent episodes of local contamination, the modular design of the atmospheric station would allow for the station to be moved to a better location. Figure 1 shows a satellite view of the area of the station.

To avoid sampling locally polluted air, air sampling with a device for metal and organic pollutants analysis (modified HVS-DHA80; Digitel, Hegnau, Switzerland) was programmed to stop under calm meteorological conditions with weak winds $\left(<1 \mathrm{~m} \mathrm{~s}^{-1}\right)$, and at winds from most of the western segment.

The containers and the complete set of instruments were assembled and tested at the main office of the Norwegian Institute for Air Research (NILU), Kjeller, Norway, in summer 2006. The atmospheric station was 
Table 1 Instrument and parameter overview of Troll Atmospheric Station.

\begin{tabular}{|c|c|}
\hline Instrument & Parameter observed \\
\hline TSI-3563 Integrating Nephelometer (TSI, Shoreview, MN, USA) & Light scattering and absorption by aerosols $\rightarrow$ single scattering albedo \\
\hline $\begin{array}{l}\text { Differential Mobility Particle Sizer (DMPS), including a Differential } \\
\text { Mobility Analyzer (Hauke, Gmunden, Austria) }\end{array}$ & Aerosol size distribution \\
\hline Soot absorption photometer (custom-built) & Aerosol light absorption \\
\hline $\begin{array}{l}\text { EK Sequential Air Sampler (Norwegian Institute of Air Research, Kjeller, } \\
\text { Norway) }\end{array}$ & $\begin{array}{l}\text { Collection of gases and aerosols: European Monitoring and Evaluation } \\
\text { Programme (EMEP) main components }\end{array}$ \\
\hline Precision Filter Radiometer (PMOD/WRC, Davos, Switzerland) & Aerosol optical density (AOD) \\
\hline Sky View PSV-100H (Prede, Tokyo, Japan) & All-sky images \\
\hline NILU-UV (Norwegian Institute of Air Research, Kjeller, Norway) & $\begin{array}{l}\text { UV irradiance at four wavelengths, PAR } \rightarrow \text { total ozone, effective surface } \\
\text { reflectance }\end{array}$ \\
\hline $\begin{array}{l}\text { 2537A Mercury Vapour Analyzer (Tekran Instruments Corporation, } \\
\text { Knoxville, TN, USA) }\end{array}$ & Gaseous elementary mercury (GEM) \\
\hline $\begin{array}{l}\text { 400E UV Absorption Ozone Analyzer (Teledyne Instruments, City of } \\
\text { Industry, CA, USA) }\end{array}$ & In-situ ozone concentration \\
\hline $\begin{array}{l}\text { AL5002 Very Fast Carbon Monoxide Monitor (Aero-Laser GmbH, } \\
\text { Garmisch-Partenkirchen, Germany) }\end{array}$ & In-situ CO mixing ratio (ppbV) \\
\hline DHA80 High Volume Sampler (Digitel, Hegnau, Switzerland) & Air samples for analysis of POPs/PAHs \\
\hline Flask sampling & Analysis of NMHCs, CFCs concentration \\
\hline WXT510 Weather Transmitter (Vaisala, Vantaa, Finland) & $\begin{array}{l}\text { Standard meteorological parameters (temperature, pressure, wind strength } \\
\text { and direction, relative humidity, precipitation) }\end{array}$ \\
\hline
\end{tabular}

shipped to Antarctica in austral summer 2006/07, and was re-assembled at Troll Station in January and February 2007. The first measurements of single instruments were started in late January, and the complete measurement programme was in operation by mid-February.

\section{Measurement programme and instruments}

The monitoring programme at Troll Atmospheric Station (TAS) covers a wide range of parameters, which requires a composed set of methods and instruments, including active probing and passive measurements. The complete set of instruments and parameters observed is given in Table 1. Most of the data are available nearly real time via internet connections, but filter and air samples are shipped from Troll to NILU only during the austral summer.

\section{Meteorological measurements}

Standard meteorological parameters are monitored by means of a Vaisala WXT510 system (Vantaa, Finland). Temperature, pressure, wind speed and direction, relative humidity and precipitation are monitored with a resolution of one minute. As this sensor is not an official World Meteorological Organization station (the Norwegian Meteorological Institute runs another meteorological station at the Troll main station), no calibration efforts have been made, apart from those provided by the manufacturer in Vaisala. (The technical specifications of the sensor are found at http://www.vaisala.com/ instruments/products/weathermultisensor.html.) This system is, by default, coupled to the air sampling control unit (Digitel, Hegnau, Switzerland). To avoid local contamination of the measurements, which would completely dominate the pristine pollution levels, the controller is programmed to stop sampling when the wind speed is less than $1 \mathrm{~m} \mathrm{~s}^{-1}$ or when the wind blows from the $189-349^{\circ}$ segment (approximately from SSW to NNW). In these cases, the meteorological information is discarded.

In the data set for 2007, which only lacks the period 1-19 January from the complete annual cycle, these conditions were present during $3.8 \%$ of the operation period. Adding the first 19 days of 2008 changes these numbers by only $0.1 \%$. In this sense, the meteorological record can be regarded as practically complete. Nevertheless, a second weather monitoring system, independent of the sampling control unit, was installed in the austral summer 2007/08, not only to get a complete data set, but also to increase the temporal resolution.

Figure 2 shows the complete records of the hourly means of four meteorological parameters during 2007. Temperature, pressure, wind strength and wind direction are compared with meteorological recordings at the Troll Airfield (located on the inland ice, approximately $7 \mathrm{~km}$ away from the station). The pressure at the station is, on average, $8 \mathrm{hPa}$ lower than at the airfield, which is in reasonable agreement with the altitude difference of $60 \mathrm{~m}$, taking into consideration an accuraacy of $1 \mathrm{hPa}$ in the Vaisala sensor at the mean temperature of the station. The temperature is systematically higher at the station, 

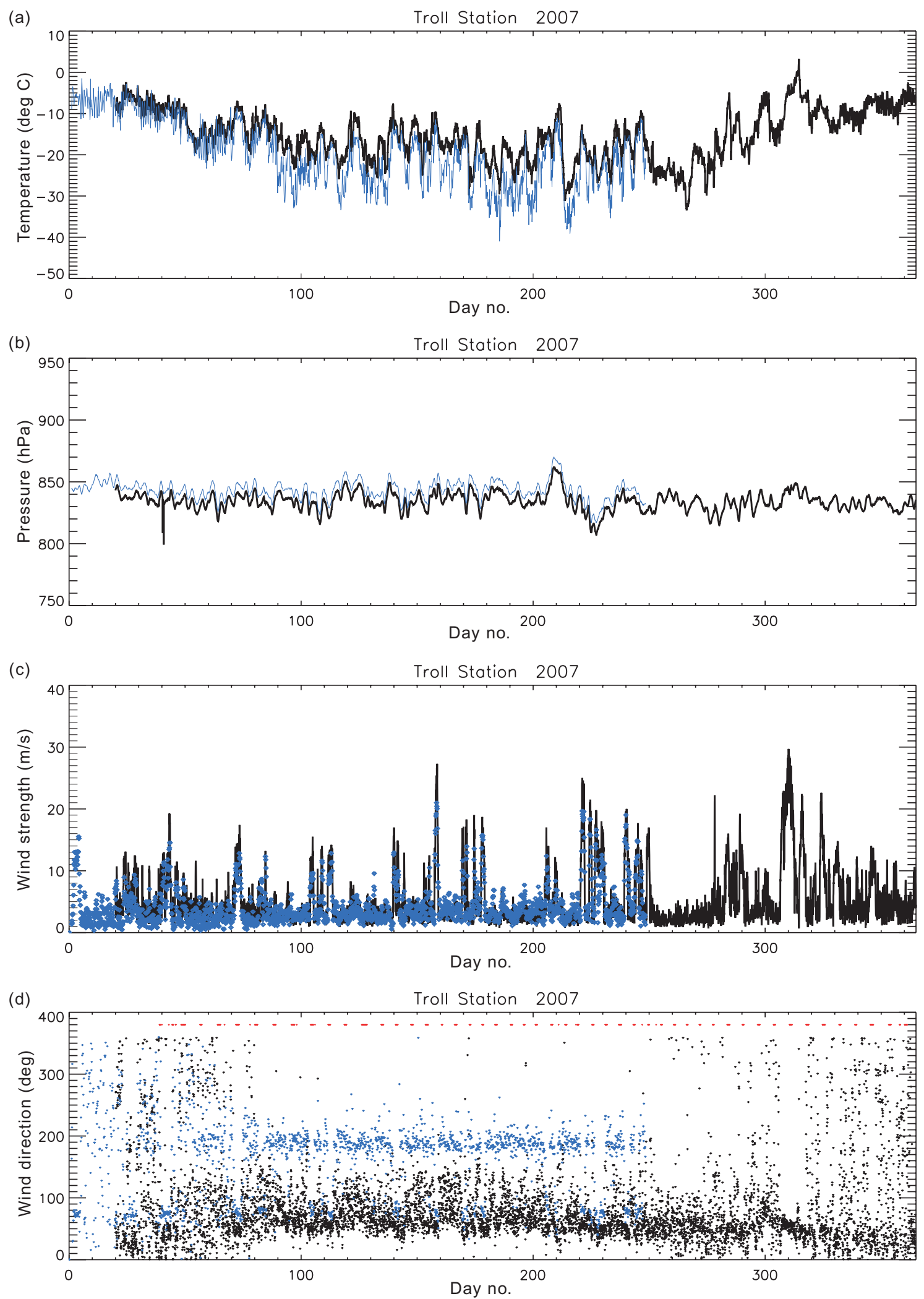

Fig. 2 Basic meteorological parameters, as measured at the Troll Atmospheric Station in 2007: (a) temperature, (b) pressure, (c) wind strength and (d) wind direction (blue dots). Blue: measurements at Troll Airfield. The red dots in (d) are times when the measurements were discarded in order to avoid local contamination (see text). 
up to $10^{\circ} \mathrm{C}$ in winter, but less than $2^{\circ} \mathrm{C}$ in summer. Moreover, the daily cycle is larger on the ice than at the station. This is also as expected, with the coldest air masses found at the location with the lowest elevation.

Regarding the wind strength and direction, which are shown as a polar diagram in Fig. 3, the topography obviously has a noticeable influence on these parameters at TAS. During the winter half-year, winds blow almost exclusively from a narrow sector (40-140; i.e., NE-ESE), with a median around $55^{\circ}$. Strong winds $\left(>15 \mathrm{~m} \mathrm{~s}^{-1}\right.$ hourly mean) all originate from an even narrower sector $\left(40-70^{\circ}\right)$. During the summer months, winds are scattered much more across the whole scale of directions, but with a median at around $30^{\circ}$. At Troll Airfield, winds are generally weaker (up to $8 \mathrm{~m} \mathrm{~s}^{-1}$ during gales), and the pattern is different. Strong winds come from a very narrow sector $\left(70-85^{\circ}\right)$, whereas weak winds, especially in winter, originate from $185 \pm 15^{\circ}$ (southerly). The differences between the two sites are probably caused by the wind funnelling conditions at TAS, which is located

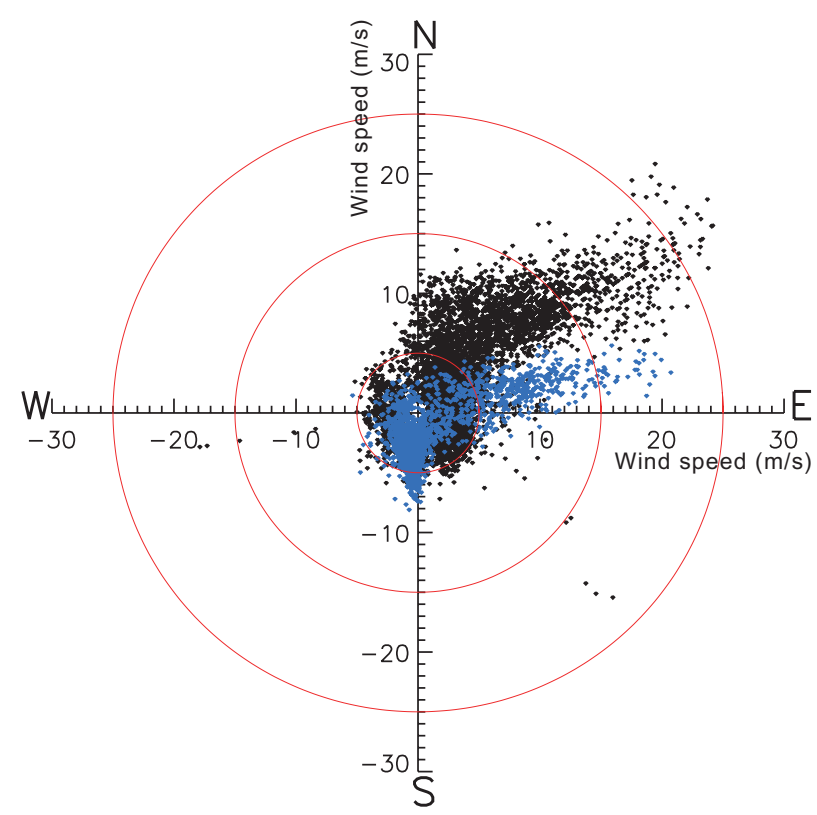

Fig. 3 Polar diagram of wind at Troll Atmospheric Station (black dots) and Troll Air Field (blue dots). between the Sofietoppen ridge and the main massif of the Troll nunatak. These conditions cause a harsher local environment, but they also reduce the probability of local pollution.

\section{Aerosol measurements}

Aerosols are monitored at TAS with respect to physical, chemical and optical properties. The complete set of instruments and properties monitored is given in Table 2 .

The Precision Filter Radiometer measures direct solar radiation at four different wavelengths (862, 501, 412 and $368 \mathrm{~nm}$ ) in four independent channels, from which aerosol optical density (AOD) and the Angström coefficient $\alpha$ are derived. Before being shipped to Antarctica, the instrument was calibrated twice at the PMOD/WRC Calibration Centre in Davos (October 2005 and January 2007). In this time period, the UV channel (368 nm) changed by about $1.7 \%$, whereas the other channels were stable within $1 \%$. This comprehensive data set is suited to separate local from long-transported components (soot photometer plus CO monitor), lower level aerosols from the tropopause region and stratospheric particles (sun photometer plus sky imager), and continental from coastal/marine aerosols (nephelometer, differential mobility particle sizer). A preliminary analysis of aerosol optical density and $\alpha$ Angstrøm coefficient in the austral autumn (30 March-8 April 2007) yields typical AOD values of $0.022 \pm 0.004$ at $500 \mathrm{~nm}$ and $\alpha$ values of $1.6 \pm 0.1$. The former are in good agreement with measurements published in a review paper by Tomasi et al. (2007). The $\alpha$ values are also in the range to be expected at a site close to typical Antarctic conditions.

The austral spring data need a very thorough analysis: most of them appear to be "contaminated" by the presence of thin tropospheric and polar stratospheric clouds, causing larger AOD values, and much smaller $\alpha$ values. Figure $4 \mathrm{~b}$ shows 500-nm AODs and $\alpha$ parameters for the period 16-22 November. The AOD values of $0.022 \pm 0.07$ and $\alpha$ Angstrøm coefficients of $1.5 \pm 0.3$ show a larger variation compared with spring values, indicative of the potential influence of larger particles. In total, we see values ranging between typical continental conditions

Table 2 Aerosol-related instruments at Troll Atmospheric Station.

\begin{tabular}{|c|c|}
\hline Instrument & Parameter measured \\
\hline $\begin{array}{l}\text { Differential Mobility Particle Sizer (DMPS), including a Differential } \\
\text { Mobility Analyzer (Hauke, Gmunden, Austria) }\end{array}$ & Particle number size distribution $(0.20-0.75 \mu \mathrm{m})$ \\
\hline TSI-3563 Integrating Nephelometer (TSI, Shoreview, MN, USA) & Particle scattering and backscattering coefficients at three light wavelengths \\
\hline Soot absorption photometer (custom-built) & Particle absorption coefficient at one light wavelength \\
\hline Precision Filter Radiometer (PMOD/WRC, Davos, Switzerland) & Aerosol optical depth at four light wavelengths \\
\hline Particle samples on filters & Organic and inorganic speciation \\
\hline
\end{tabular}


(a)

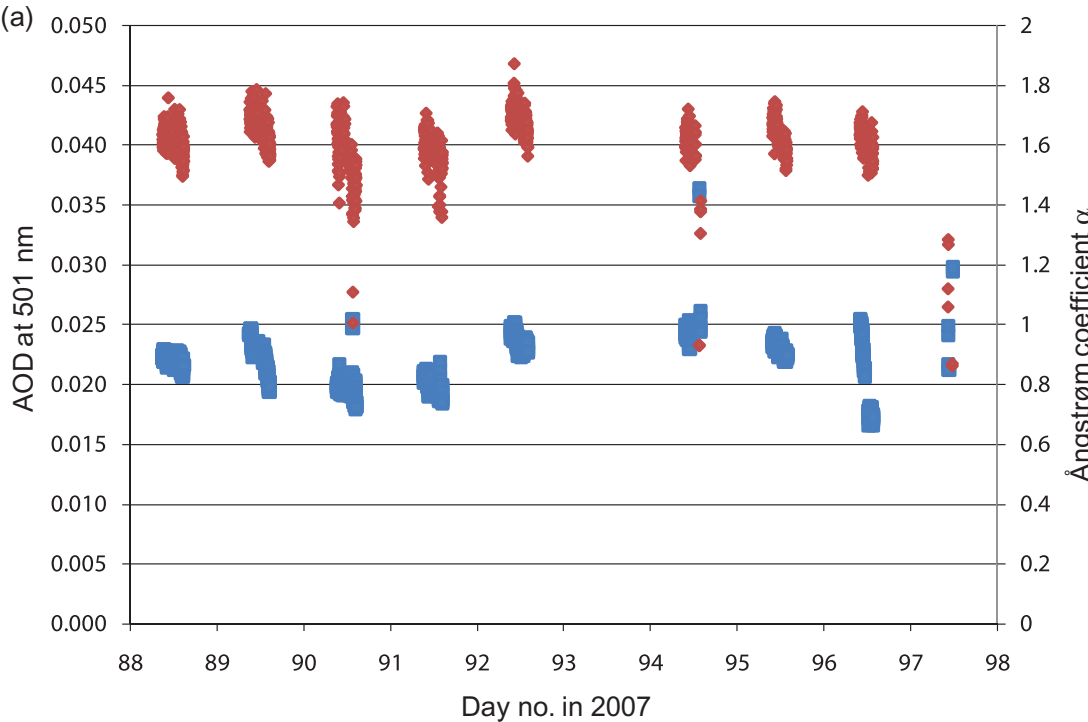

(b)

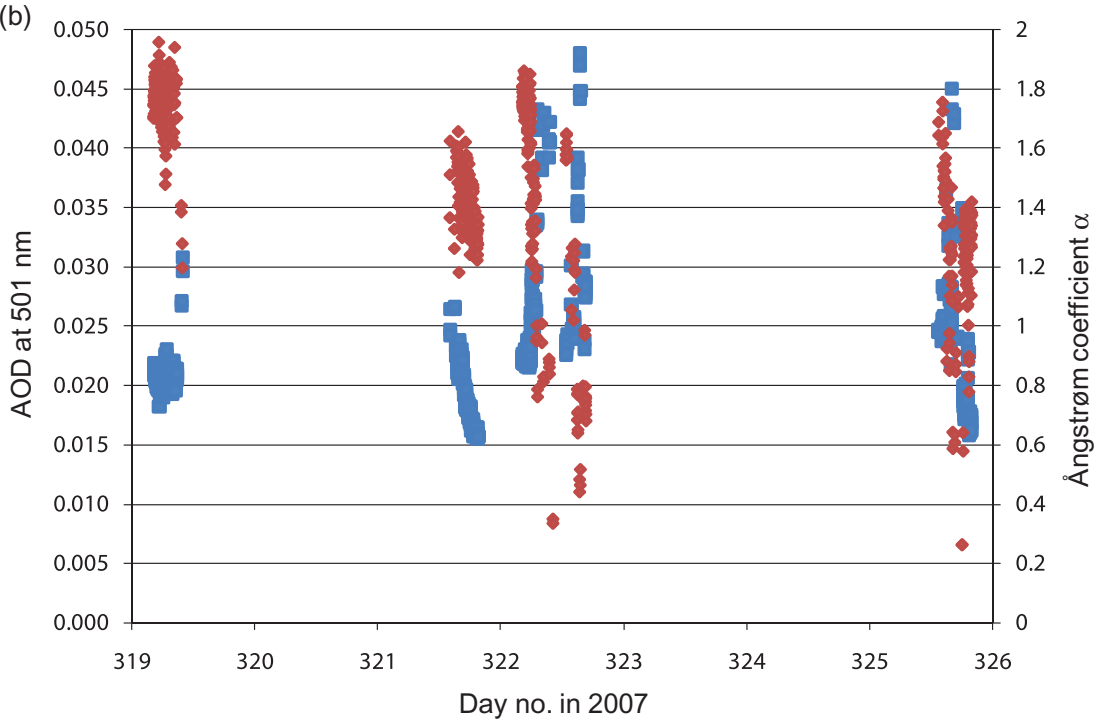

Fig. 4 Aerosol optical density (AOD) at $500 \mathrm{~nm}$ and Ångstrøm parameter $\alpha$, as measured with the the Precision Filter Radiometer instrument on: (a) days 89-98 and (b) days 319-326. and those found in coastal measurements. A comprehensive publication on physical properties, chemical composition, combined with transport modelling, is in preparation.

\section{UV/PAR doses and total ozone}

Doses of ultraviolet (UV) and photosynthetically active radiation (PAR) are measured by means of a multichannel medium-bandwidth filter instrument called NILU-UV, developed and produced by NILU. Details about the instrument and its performance are found in Høiskar et al. (2003). A small network of NILU-UV instruments has already been in operation in South America and Antarctica since 1999 (Redondas et al. 2008), and the
Troll instrument will further enhance this network, e.g., for ozone hole monitoring and satellite validation purposes. The instrument is virtually maintenance-free, but should be calibrated once a month by means of relative lamps, and once a year the instrument should be calibrated against a National Institute of Standards and Technology (NIST)-traceable standard. For this reason, two instrument heads, which can be exchanged during the summer season, are used alternately. The relative lamp calibration performed once a month follows a strict procedure (see Redondas et al. 2008). A special fitted lamp unit is placed in front of the sensor, and data are recorded from three different lamps in sequence. The use of three different lamps reduces the risk of not detecting severe change in the calibration lamp, as such a change 
Fig. 5 Total ozone values (daily means) derived from the Troll NILU-UV instrument (blue). For comparison, measurements with the satellite-borne Ozone Monitoring Instrument (OMI) near Troll (green) and total ozone derived from ozonesondes launched at Neumayer Station (yellow) are shown. Black squares with error bars and spline fit: monthly total ozone means derived from satellite measurements at Troll before 1981 (Backscatter Ultraviolet and Total Ozone Mapping Spectrometer), i.e., under pre-ozone-hole conditions. Red lines: period with maximum solar elevation $<8^{\circ}$ (GUV data not reliable).

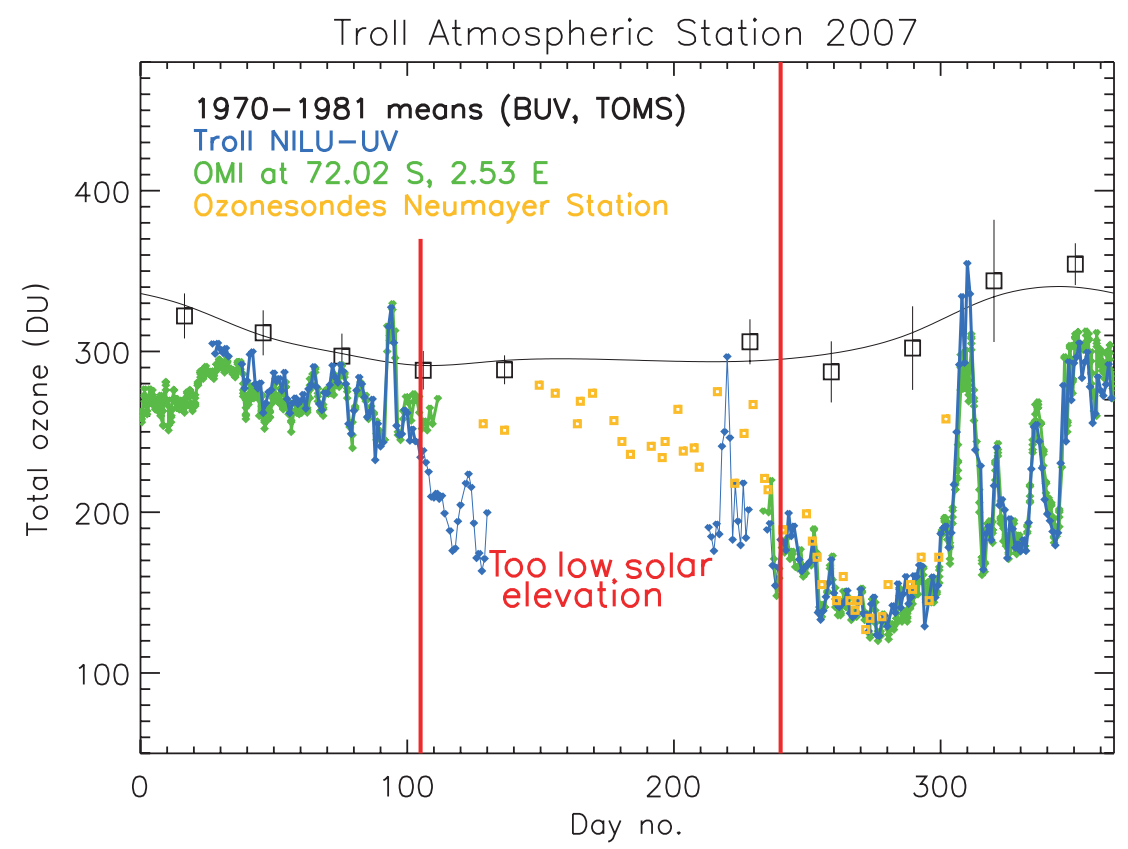

could be misinterpreted as a change in the instrument sensitivity or optical characteristics of the sensor. Usually, this kind of instrument tends to slowly change in sensitivity on the order of a few percent per year. By fitting a function to the sensitivity change, it is possible to correct the data before the actual analyses (Redondas et al. 2008).

Figure 5 shows the total ozone record as measured with the NILU-UV in 2007. From day 110 to day 235, the minimum solar zenith angle is larger than $82^{\circ}$, and under these conditions total ozone values become rather uncertain, as they strongly depend on various parameters, e.g., the vertical distribution of ozone. Only with comprehensive modelling efforts (which could not be performed within the frame of this overview) could the period providing data of acceptable quality be extended by about two weeks on either side of the polar night. For comparison, total ozone measurements from the Ozone Monitoring Instrument (OMI) satellite instrument are shown, indicating a very good agreement between the two data sets, except for a few days around day 310 , when the edge of the ozone hole passed over the station. In this case, the geographical gradient is very large, so that the distance between the ground site and the footprint of the satellite measurement may severely affect the agreement. The figure also shows a pre-ozone-hole monthly mean climatology, based on total ozone measured by the Backscatter Ultraviolet (BUV) instruments and Total Ozone Mapping Spectrometer (TOMS) satellite instruments in the period 1970-1981. It indicates that the ozone hole influences the total ozone level throughout the whole year, with ozone reductions of up to $20 \%$ after the polar vortex has broken down.

UV doses are higher by at least a factor of three during ozone hole conditions than at a conjugate location in the Northern Hemisphere, such as the Arctic Lidar Observatory for Middle Atmospheric Research in northern Norway (measured with a GUV filter instrument, which is technically very similar to the NILU-UV), as illustrated in Fig. 6. To get the seasonal match with the Northern Hemisphere site, Troll measurements from the first half of 2007 were shifted by +183 days, whereas measurements from the second half-year were shifted by -183 days.

\section{Measurements of tropospheric pollutants}

Tropospheric compounds are monitored using various methods, and with varying temporal resolution. Surface ozone, CO, soot and mercury are measured quasicontinuously with a time resolution of 1 min to 1 hour. These data are available nearly real time.

Concentrations of other inorganic (European Monitoring and Evaluation Programme [EMEP]) main components in air are derived from 1-week filter samples; the same sampling strategy (integration over l week) is applied for POPs. NMHCs and chlorofluorocarbons (CFCs) are determined from flask samples taken once per week, but they give an instantaneous ( 1 min filling time), not an integrated, picture of trace gas concentrations. The samples are collected for a whole year, to be transported to NILU, where they are prepared, analysed and quantified after the austral summer. NILU conducted campaign- 


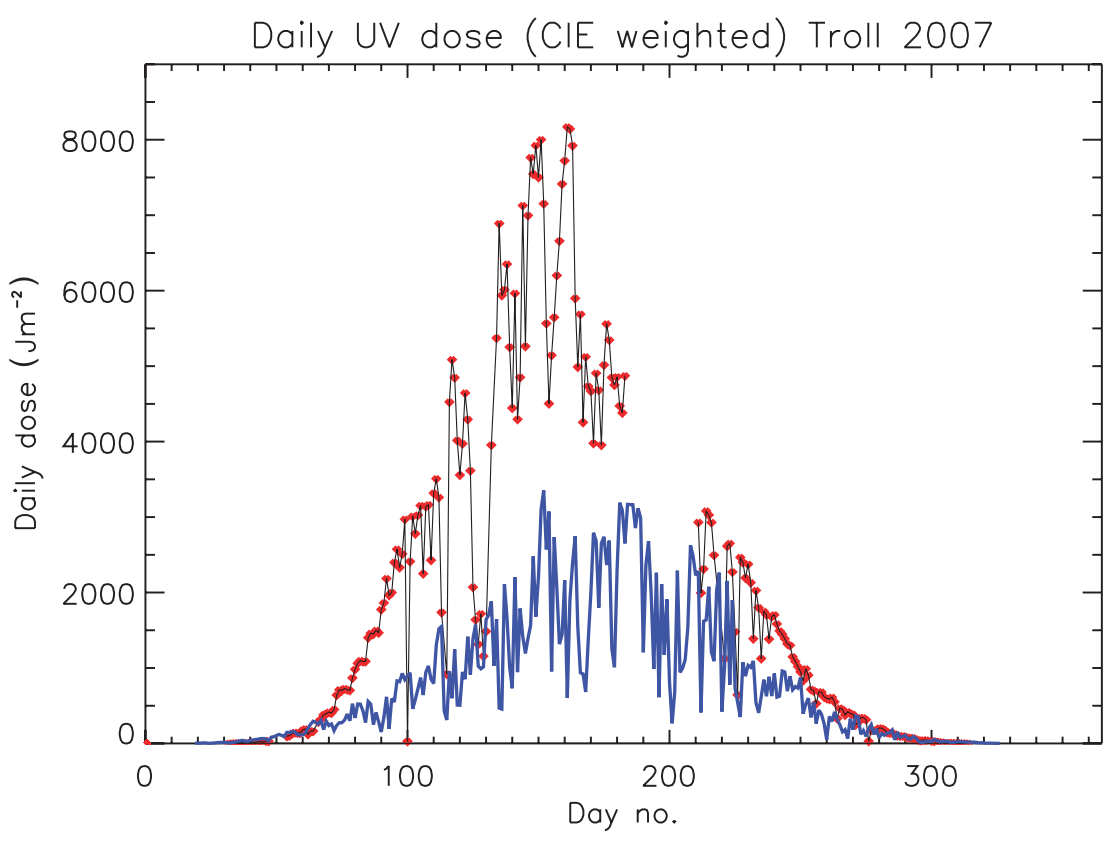

Fig. 6 Erythemal Commission Internationale de l'Eclairage (CIE)-UV daily doses from 2007, as measured with the ALOMAR GUV filter instrument (blue line), compared with doses measured at Troll (black line, red diamonds). Troll data are offset by 183 days (January-April) and -183 days (August-December), respectively, to compensate for the seasonal offset between the two sites. based POP surveys in Antarctic air as early as in 1994 at Signy Island (South Georgia), in close co-operation with the British Antarctic Survey (Kallenborn et al. 1998). All 2007 POP samples have been quantified in early 2008. Compared with the long-term atmospheric POP monitoring programme in the Arctic (Zeppelin Station for Air Monitoring and Research, Ny-Ålesund, Svalbard), considerably lower levels have been determined for all target contaminants at the Troll Station. Detailed scientific assessments of concentration levels, pattern distributions and atmospheric long-range transport events will be discussed in a dedicated publication.

Soot and CO data are used both scientifically and to identify and exclude episodes of local pollution. These may occur either under calm conditions with weak winds blowing from the main building or in the vent of the operation of motorized vehicles in the vicinity of the atmospheric station. Figure 7 shows 1 -min resolution CO data not yet corrected for instrument changes between two subsequent calibrations (every $6 \mathrm{~h}$ ). The background level of approximately $40 \mathrm{ppb}$ (rising to $46 \pm 5 \mathrm{ppb}$ during March) is less than $50 \%$ of levels found at the comparable Arctic site of Zeppelin Station, where typically levels of $120 \mathrm{ppb}$ are found in September. The short-lived spikes above the background level probably represent local pollution episodes from the main building or the use of vehicles: this has to be analysed in more detail.

The concentration of gaseous elementary mercury (GEM) has been measured with 5-min time resolution, by applying a $2537 \mathrm{~A}$ mercury vapour analyser (Tekran
Instruments Corporation, Knoxville, TN, USA). The instrument was calibrated every $23 \mathrm{~h}$, using the provided internal calibration source. Additionally, accuracy of the analyser is verified once per year by manual injections of known quantities of $\mathrm{Hg}(0)$. The average annual GEM concentration is $0.92 \mathrm{ng} \mathrm{m}^{-3}$, which is comparable with measurements conducted at the Neumayer Station (Ebinghaus et al. 2002) and Terra Nova Bay (Sprovieri et al. 2002). Concentrations show a similar ratio to Arctic levels as CO, where GEM levels are around $1.6 \mathrm{ng} \mathrm{m}^{-3}$ (Berg et al. 2003; Slemr et al. 2003). Austral spring and summer measurements show GEM depletion events, which exhibit a strong positive correlation with tropospheric ozone, as also observed in the Arctic (Schroeder et al. 1998; Berg et al. 2003).

The atmospheric in-situ concentration of ozone was measured at the Troll Station from the beginning of January 2007. After a period of instrument checks, calibration procedures, and so on, reliable data were monitored from February on a continuous basis. A standard ozone monitor is used (model API 400E; Teledyne Technologies, San Diego, CA, USA), where ozone molecules are detected by the absorption of UV light (254 nm) emitted by an internal mercury lamp. Light from the lamp illuminates a hollow quartz tube that is alternately filled with sample gas and gas scrubbed to remove ozone. The ratio of the intensity of light passing through the scrubbed gas to that of the sample forms a ratio $I: I_{0}$. The concentration of ozone is calculated from this ratio, pressure and temperature by using the BeerLambert equation. The concentrations are measured at 
Fig. 7 CO concentration (ppbV) as measured in March 2007 at Troll, with a 1-min time resolution. Data are not corrected for drift between individual calibrations (taken approximately every $6 \mathrm{~h}$ ).

Fig. 8 In-situ surface ozone measurements (daily means) from February to August 2007 at Troll (black line). Data are compared with measurements from Zeppelin Station, in the Arctic, in 2005 (blue line), offset by 6 months (183 days) in order to achieve a season match.
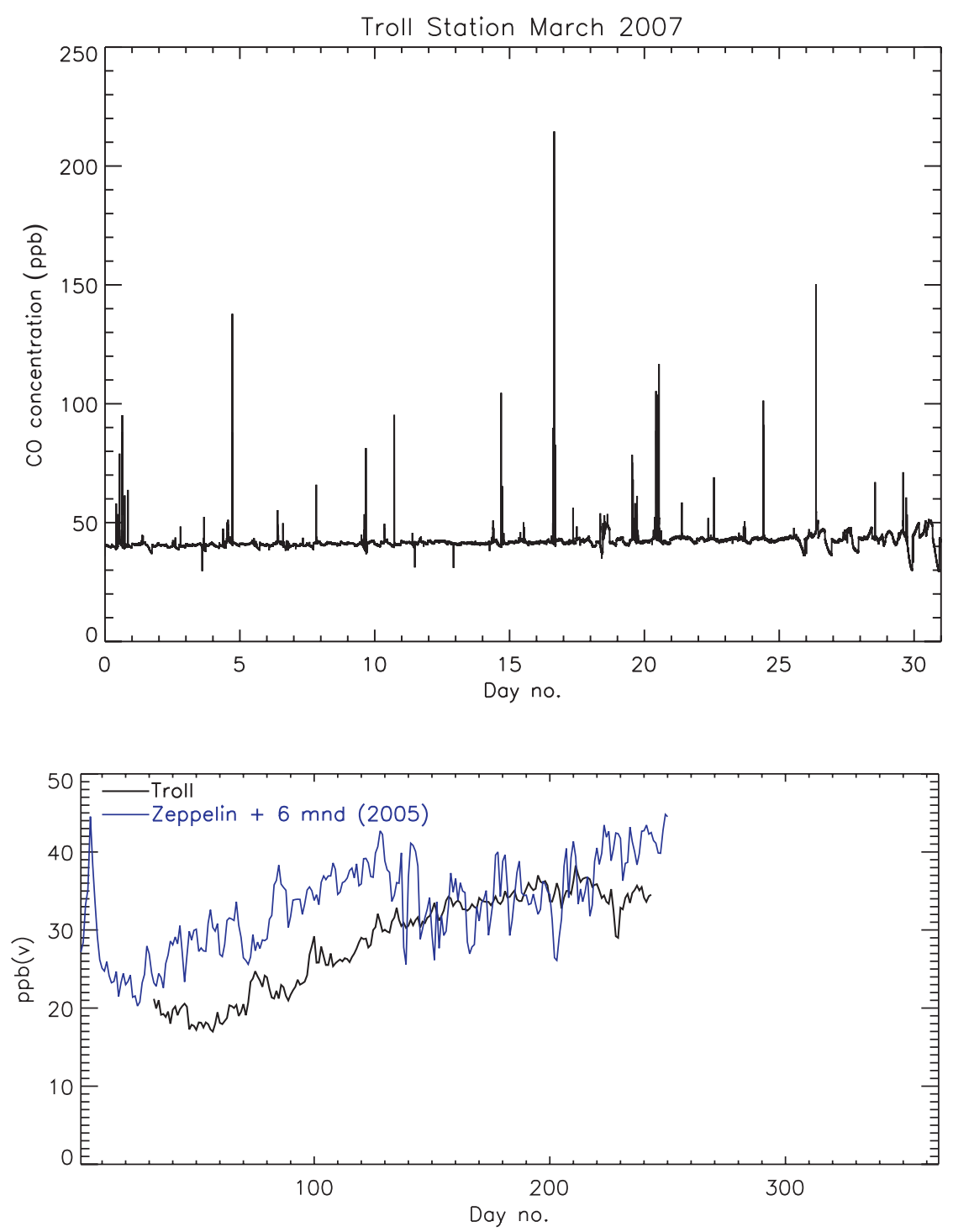

1-min resolution, and are subsequently averaged and stored as hourly averages. A weekly zero/span check is performed by an internal source within the monitor, remotely controlled from NILU. The inlet filter is replaced approximately every third month, and the inlet tube is replaced annually. An annual calibration with a NISTtraceable transfer standard ozone calibrator is scheduled, and the monitor itself will be replaced every third year by a renovated and calibrated monitor.

Daily mean data from the period February-August 2007 are shown in Fig. 8, together with daily ozone means measured at Zeppelin Station, Svalbard (2005), with a time lag of 6 months, in order to achieve a season match. During the first 4 months, the ozone concentrations from Troll were clearly lower than the ones from Svalbard (from August to November), by approximately
10 ppbv. However, in June and July the average concentration at Troll was close to the one at Spitsbergen (from December and January). The ozone data from Zeppelin reveal large variability, which is reasonable, and reflects the higher frequency of transport episodes from more polluted regions than one can expect at Troll.

A preliminary analysis of the major inorganic constituents from filter probes in the period 13 February-15 October reveals the varying influence of continental and marine air masses at Troll throughout the winter season, even in mid-winter. For example, the highest values of $\mathrm{NA}^{+}, \mathrm{Cl}^{-}$and $\mathrm{K}^{+}$of the 39 samples analysed are found on 18 June. This coincides with a period of strong winds blowing from the north-east, both at the TAS and at the Troll Airfield. Figure 9a shows the concentrations of $\mathrm{Cl}^{-}$, $\mathrm{Na}^{+}$and $\mathrm{K}^{+}$(weekly accumulation) in 2007, which are 

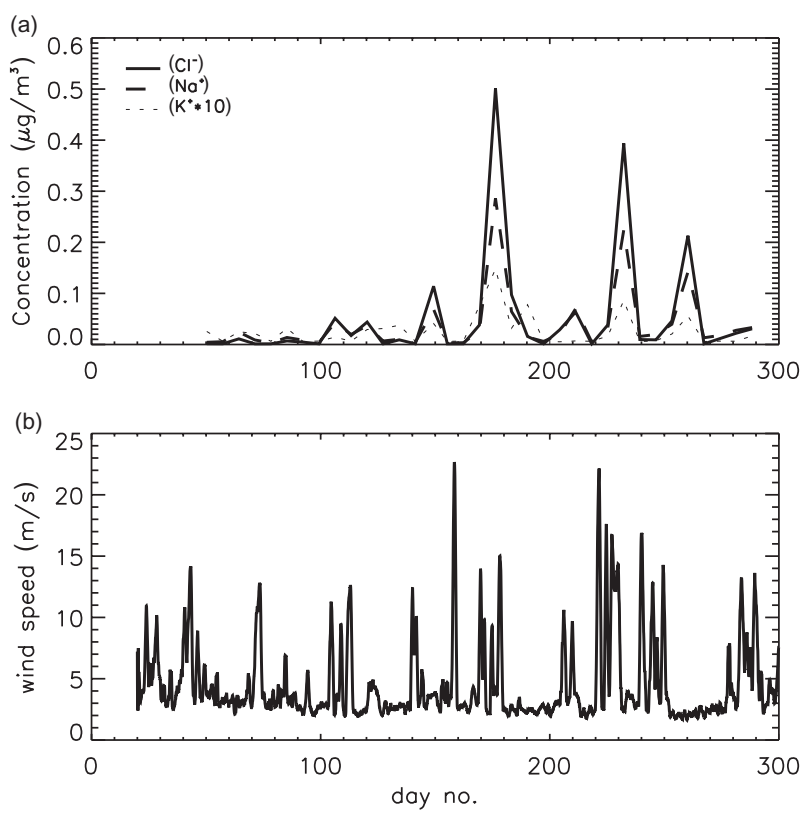

Fig. 9 (a) Concentration of $\mathrm{Cl}^{-}, \mathrm{Na}^{+}$and $\mathrm{K}^{+}$ions in filter probes taken at Troll in 2007. The $x$ value gives the day number of the end of the respective sampling period. $\mathrm{K}^{+}$is multiplied by a factor of 10 . (b) Windspeed, smoothed over $23 \mathrm{~h}$.

highly correlated. Comparison of the ion concentrations with the wind speed (Fig. 9b) indicates that probes with high concentrations follow episodes of high wind speeds. The increasing delay from the austral autumn to spring may be indicative of the markedly increasing distance between the station and the open ocean as sea ice develops.

Air samples of POPs/polycyclic aromatic hydrocarbons (PAHs) are taken in the same way and with the same equipment as at Zeppelin Station: a DH80 high-volume sampling unit (Digitel, Hegnau, Switzerland). The only difference is the sampling time, which is $48 \mathrm{~h}$ per sample at Zeppelin Station and 7 days at TAS, because of the lower concentrations in Antarctica compared with the Arctic. POP samples from TAS will be analysed according to the same routines as samples from Zeppelin Station. This guarantees an optimum comparability of pollution levels at the two sites. The first year-round set of POP measurements in Antarctica was analysed recently; a dedicated publication is in preparation.

\section{Air archive}

NILU is also establishing an archive of air samples in large high-pressure cylinders. Twice every year-around the time of the expected minimum and maximum of the annual cycle-a 34-liter ESSEX stainless steel canister is filled with 2000 litres of air. The sampling is performed cryogenically at liquid nitrogen temperature without using pumps, flow controllers or driers-excess air humidity is removed by venting in an upside-down position. The samples are transported to NILU once a year. The samples will be analysed twice a year in order to check for stability or drift for certain compound groups.

\section{Discussion and conclusions}

The new Antarctic year-round atmospheric monitoring station at Troll has completed its first annual cycle of measurements. Preliminary results indicate that although the station is rather close to the main building of Troll Station, measurements are only affected by local pollution to a limited degree. A final decision on whether the atmospheric measurements can continue at the present location or whether the station should be moved further away from the main station building will be taken within two years' time.

The first year of operations has been very encouraging from a technical point of view. All instruments worked as scheduled, unaffected by the rough meteorological conditions in high-elevation Antarctica or the local conditions of the wind funnelling at Troll in particular.

The NILU-UV ozone and UV measurements have proven their quality in a comparison with both spaceborne and ground-based measurements in the region, and appear fully suited to be used for validation purposes. Aerosol observations are in good agreement with other measurements from the region, considering the specific conditions of the station. They confirm that Troll indeed is of special interest as a site in the transition region between the Antarctic coastal zone and the Antarctic Plateau. Even in mid-winter, marked episodes of coastal influence and long-range transport are evident.

Year-round measurements of nitrate $\left(\mathrm{NO}_{3}{ }^{-}\right)$in continental Antarctica have previously been reported for the Köhnen site (situated $520 \mathrm{~km}$ from the coast) (Weller $\delta$ Wagenbach 2007) and for certain coastal sites (Wagenbach et al. 1998). According to Wagenbach et al. (1998), stratospheric nitrate may be the dominant source of nitrate in Antarctica, provided by intrusion of stratospheric air masses and sedimentation of polar stratospheric clouds. For areas of Antarctica experiencing small levels of snow accumulation per year, typically the continental parts, re-emission of $\mathrm{HNO}_{3}$ from the snow surface may be important. According to Wagenbach et al. (1998), continental tropospheric sources of nitrate are probably of minor importance to the observed concentrations of nitrate in Antarctica. The relative strength of the various sources and their influence on the seasonal cycle still remains uncertain. 
The Troll values are somewhat lower than those reported for other sites in Antarctica during year-round sampling (17-36 $\mathrm{ng} \mathrm{m}^{-3}$ ) (Savoie et al. 1992; Wagenbach et al. 1998; Weller \& Wagenbach 2007), but they are not too far off the annual mean reported for the continental Köhnen site $\left(25 \pm 21 \mathrm{ng} \mathrm{m}^{-3}\right)$. As already mentioned above, this may partly result from the fact that the months during which the highest values are found at other sites are not yet included in the data. The seasonal variation also resembles that observed for the continental site Köhnen and coastal sites (Neumayer and Dumont d'Urville) in several ways, i.e. minimum concentrations are observed during winter (May-June), whereas the concentration starts to increase in late summer towards the peak in late spring (November at other stations). A full year of sampling is necessary to conclude whether the similarity extends beyond that of the 9 months of sampling.

Levels of inorganic compounds such as $\mathrm{CO}$ and $\mathrm{Hg}$ are clearly lower (by about $40 \%$ ) than in high northern latitudes, but still reach significant values. Inorganic salt ion concentrations are clearly linked to meteorologically disturbed episodes (strong north-easterly winds), with marine air masses reaching the Antarctic slope. There are also indications that GEM depletion events are seen at Troll. We are looking forward to a detailed analysis of POPs with respect to composition and annual variation, which should give new insight in the transport mechanisms of pollution from low to high latitudes.

\section{Acknowledgements}

The atmospheric monitoring and research programme at Troll Station is mostly funded by the Norwegian Antarctic Research Expeditions programme, administered by the Norwegian Polar Institute (NPI). We are also very grateful to the excellent technical support by the NPI staff during the establishment phase of the station, and to their continuous support in the operational phase of the programme. Access to ozonesonde data from Neumayer Station via the NADIR database, and to OMI total ozone data at ftp://toms.gsfc.nasa.gov/pub/omi/data/ozone, is gratefully acknowledged.

\section{References}

Berg T., Sekkesæter S., Steinnes E., Valdal A.K. \& Wibetoe G. 2003. Springtime depletion of mercury in the European Arctic as observed at Svalbard. Science of the Total Environment 304, 43-51.

Ebinghaus R., Kock H.H., Temme C., Einax J.W., Lowe A.G., Richter A., Burrows J.P. \& Schroeder W.H. 2002. Antarctic springtime depletion of atmospheric mercury. Environmental Science and Technology 36, 1238-1244.

Høiskar B.A.K, Haugen R., Danielsen T., Kylling A., Edvardsen K., Dahlback A., Johnsen B., Blumthaler M. \& Schreder J. 2003. Multichannel moderate-bandwidth filter instrument for measurement of the ozone-column amount, cloud transmittance, and ultraviolet dose rates. Applied Optics 42, 3472-3479.

Kallenborn R., Oehme M., Wynn-Williams D.D., Schlabach M. \& Harris J. 1998. Ambient air levels and atmospheric long-range transport of persistent organochlorines to Signy Island, Antarctica. Science of the Total Environment 220, 167-180.

Redondas A., Torres C., Meinander O., Lakkala K., García Cuevas E., Ochoa H., Deferrari G. \& Díaz S. 2008. Antarctic network of lamp-calibrated multichannel radiometers for continuous ozone and UV radiation data. Atmospheric Chemistry and Physics Discussions 8, 3383-3404.

Savoie D.L., Prospero J.M., Oltmans S.J., Graustein W.C., Turekian K.K., Merrill J.T. \& Levy II H. 1992. Sources of nitrate and ozone in the marine boundary layer of the tropical North Atlantic. Journal of Geophysical Research-Atmospheres 97, 11 575-11 589.

Schroeder W.H., Anlauf K., Barrie L.A., Lu J.Y., Steffen A., Schneeberger D.R. \& Berg T. 1998. Arctic springtime depletion of mercury. Nature 394, 331-332.

Slemr F., Brunke E.-G., Ebinghaus R., Temme C., Munthe J., Wängberg I., Schroeder W., Steffen A. \& Berg T. 2003. Worldwide trend of atmospheric mercury since 1977. Geophysical Research Letters 30, article no. 1516, doi: 10.1029/2003GL016954.

Sprovieri F., Pirrone N., Hedgecock I.M., Landis M.S. \& Stevens R.K. 2002. Intensive atmospheric mercury measurements at Terra Nova Bay in Antarctica during November and December 2000. Journal Geophysical Research-Atmospheres 107, article no. 4722, doi: 10.1029/ 2002JD002057.

Tomasi C., Vitale V., Lupi A., di Carmine C., Campanelli M., Herber A., Treffeisen R., Stone R.S., Andrews E., Sharma S., Radionov V., von Hoyningen-Huene W., Stebel K., Hansen G.H., Myhre C.L., Wehrli C., Aaltonen V., Lihavainen H., Virkkula A., Hillamo R., Ström J., Toledano C., Cachorro V.E., Ortiz P., deFrutos A.M., Blindheim S., Frioud M., Gausa M., Zielinski T., Petelski T. \& Yamanouchi T. 2007. Aerosols in polar regions: a historical overview based on optical depth and in situ measurements. Journal of Geophysical Research-Atmospheres 112, D16205, doi: 10.1029/2007JD008432.

Wagenbach D., Ducroz F., Mulvaney R., Keck L., Minikin A., Legrand M., Hall J.S. \& Wolff E.W. 1998. Sea-salt aerosol in coastal Antarctic regions. Journal of Geophysical Research-Atmospheres 103, 10 961-10974.

Weller R. \& Wagenbach D. 2007. Year-round chemical aerosol records in continental Antarctica obtained by automatic samplings. Tellus Series B 59, 755-765. 